\title{
RENIN SEGRETION IN THE PERFUSED DOG KIDNEY
}

\author{
KENJIRO YAMAMOTO, TAKAMICHI HASEGAWA \\ AND JURO UEDA \\ Department of Pharmacology, Osaka City University, Medical School, Abeno-ku, Osaka \\ Received for publication June 4, 1967
}

In the previous paper (1), the present authors reported a new perfusion method, in which the kidney of a recipient dog with intact innervation was perfused with the donor's blood using an artificial heart-lung apparatus. That method revealed a good response of renal vessels to various vasoactive substances as well as good hemodynamic conditions for about one hour, following by a gradual increase of renal vascular resistance.

Such an increase in renal vascular resistance of the perfused dog kidney was also observed by several investigators $(2-5)$, who used perfusion methods somewhat different from the authors' method. But the mechanism for the increase has been left unclarified.

In the present study, it was observed that renin was liberated from the perfused kidney, and angiotensin was produced due to interaction of renin and its substrate in the perfusion circuit. The angiotensin thus formed constricted renal vessels, resulting in an increase in renal vascular resistance.

\section{MATERIALS AND METHODS}

Dogs weighing from 12 to $20 \mathrm{~kg}$ were intravenously anesthetized with pentobarbital sodium at a dose of $30 \mathrm{mg} / \mathrm{kg}$ as reported in the previous paper (1). Following evisceration, the left kidney was denervated surgically and pharmacologically, and the left renal artery was cannulated and perfused with donor's blood using an artificial heart-lung apparatus. The venous blood was led to a reservoir and oxygenated with a diskoxygenator. Two kinds of gas mixture $\left(95 \% \mathrm{O}_{2}+5 \% \mathrm{CO}_{2}\right.$ and $\left.95 \% \mathrm{~N}_{2}+5 \% \mathrm{CO}_{2}\right)$ were used in combination at a flow rate of $0.21 / \mathrm{min}$ each (Fig. 1).

To be used as perfusate, the whole dog blood or the dog blood whose plasma was replaced by Ringer's solution. The donor dog was intravenously anesthetized with pentobarbital sodium at a dose of $30 \mathrm{mg} / \mathrm{kg}$. The arterial blood was taken from the carotid artery following heparinization at a dose of $300 \mathrm{U} / \mathrm{kg}$. Heparin was added at a dose of $200 \mathrm{U} / 100 \mathrm{ml}$ to whole blood before used for perfusion. On the other hand, replacement of the plasma was made as follows: Red cells collected by centrifugation from the whole blood were washed twice with saline. Then Ringer's solution was added to the washed red cells to make the original blood volume, and human albumin and glucose were added in $4 \%$ and $100 \mathrm{mg} \%$ respectively. 


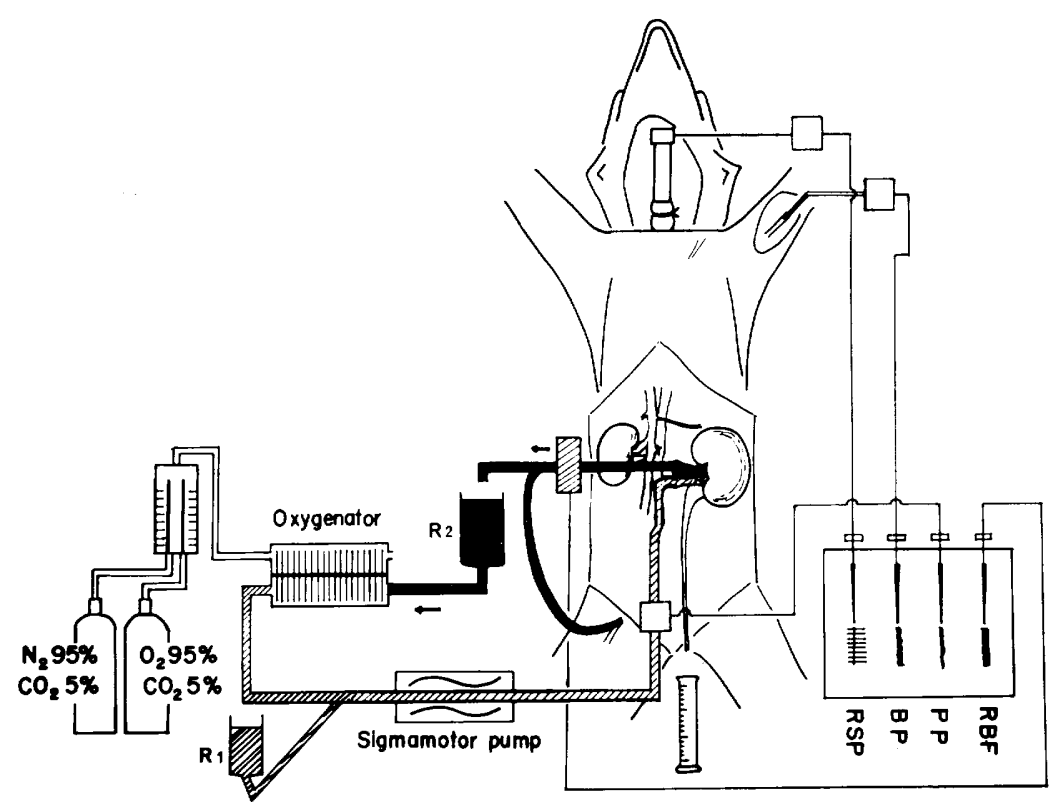

FIG. 1. Diagram of the perfusion method of the dog kidney.

A pressure transducer (Nihon Koden, Type MP-4T) and an electromagnetic flowmeter (Nihon Koden, Type MF-11) were employed in measuring perfusion pressure and renal blood flow. The left ureter was cannulated and served for urine collection. Blood samples were taken from a reservoir and the plasma was immediately separated in a cold room. The pressor activity of plasma samples was biologically assayed as follows. Wistar rats weighing from 250 to $330 \mathrm{~g}$ were anesthetized with pentobarbital sodium administered intraperitoneally in an initial dose of $35 \mathrm{mg} / \mathrm{kg}$. Subsequently they were given atropine sulfate $(1.0$ to $1.5 \mathrm{mg} / \mathrm{kg}$ ) subcutaneously and pentolinium tartarate $(2.5 \mathrm{mg} / \mathrm{kg})$ intravenously. Pentobarbital sodium and pentolinium were given supplementally when necessary. The trachea was cannulated to keep the air-way. A polyethylene tube (PE 10) was inserted into the left femoral vein to inject test solution or angiotensin standard solution within a range of 0.05 to $0.25 \mathrm{ml}$. Another polyethylene tube (PE 50) was inserted into the left femoral artery to record arterial blood pressure with a pressure transducer. The pressor activity of plasma was compared to that of standard angiotensin II (Hypertensin Ciba).

\section{RESULTS}

\section{1) Renal vascular resistance and pressor activity in the plasma}

When the kidney was perfused with the whole blood, renal vascular resistance showed gradual increase, particularly after a continued perfusion for more than one hour. The renal vascular resistance was markedly elevated following the perfusion pressure was reduced below $90 \mathrm{mmHg}$. Based on an assumption that some vasoconstrictive substance may be produced during perfusion of the kidney, the pressor activity of the plasma se- 
parated from the perfused blood was measured in anesthetized rats.

Both plasma samples obtained before and soon after the start of perfusion scarcely showed pressor activity but serial samples obtained thereafter became more and more active with the progress of perfusion, especially following a reduction of the perfusion pressure (Fig. 2). When the artificial heart-lung apparatus was operated without the kidney, no pressor activity was detected in the plasma. Therefore, it was suggested that certain pressor substance or substances were produced in the perfused kidney. When the dog blood whose plasma was replaced with Ringer's solution was used, renal vascular resistance was kept constant during perfusion with low perfusion pressure.
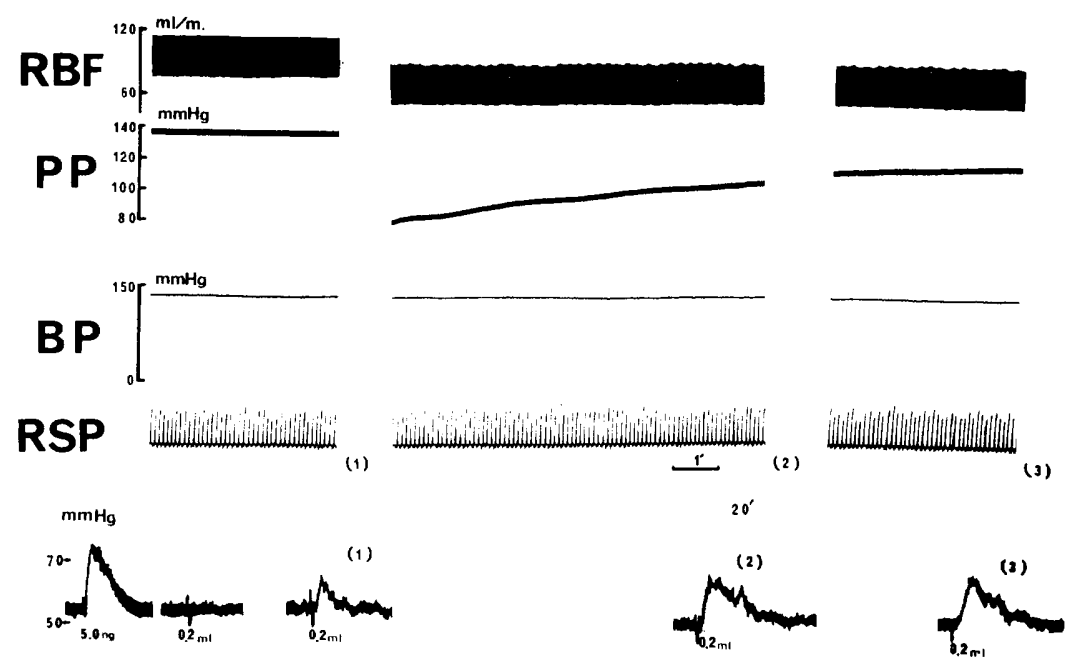

Fig. 2. Hemodynamics of the perfused kidney and the pressor activity of the plasma in the rat.

RBF : Renal blood flow

PP : Perfusion pressure

BP : Blood pressure

RSP : Respiration

The perfusion pressure was reduced to $90 \mathrm{mmHg}$ (middle part). The lowest curve shows blood pressure of the rat. From left, $5 \mathrm{ng}$ of angiotensin II, 0.2 $\mathrm{ml}$ of the plasma obtained before start perfusion, $0.2 \mathrm{ml}$ of the plasma obtained at (1), $0.2 \mathrm{ml}$ of the plasma obtained at (2), $0.2 \mathrm{ml}$ of the plasma obtained at (3).

\section{2) Nature of the pressor substance in the plasma}

Many plasma samples having a marked pressor activity were pooled in a deep freezer and used for the following experiments:

\section{A) Effect of incubation}

Two-tenths $\mathrm{ml}$ of the plasma was injected intravenously to the rats (Fig. $3 \mathrm{~A}$ ) and the same volume of the plasma which was incubated at $37^{\circ} \mathrm{C}$ for 30 minutes was similarly injected to the same rats (Fig. $3 \mathrm{~B} 1, \mathrm{~B} 2, \mathrm{~B} 3$ ). Pressor activities of these plasma samples were compared. As shown in Fig. 3, the incubated plasma (Fig. 3 B1) showed much greater pressor activity than that of the unincubated plasma (Fig. $3 \mathrm{~A}$ ). The pressor activity of the plasma incubated at pH 5.2 (Fig. 3 B2) was higher than that incubated at 


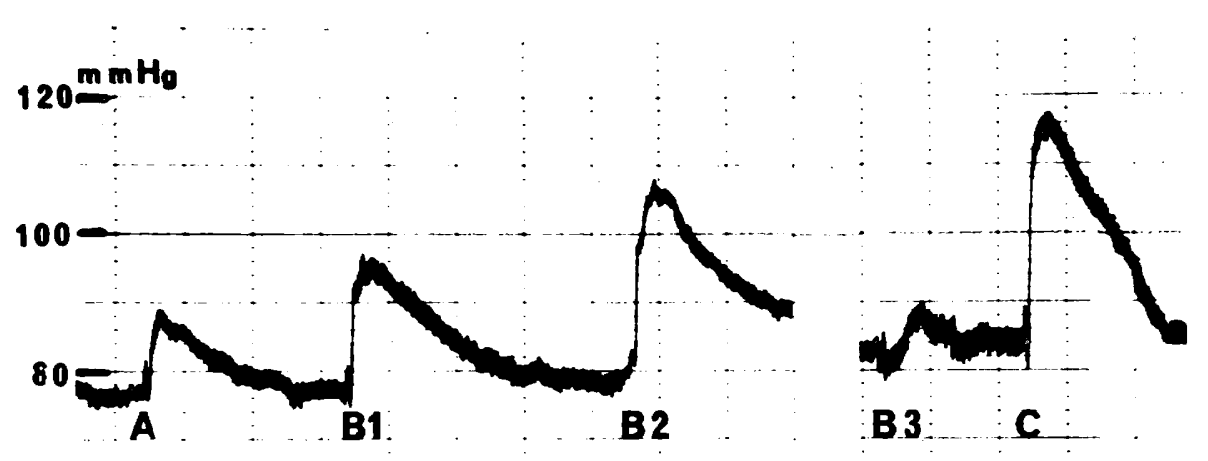

\section{A : Unincubated Plasma \\ B1: Plasma Incubated at pH 7.4 \\ B2: ; at pH 5.2 \\ B3: : at pH 2.0 \\ C : Angiotensin $7.5 \mathrm{m \mu g}$ \\ Injection Volume : 0.2}

FIG. 3. The effect of $\mathrm{pH}$ of the incubation medium on the pressor activity. Incubation time was 30 minutes.

pH 7.4 (Fig. $3 \mathrm{B1}$ ), probably due to angiotensinase activity in the plasma. At $\mathrm{pH}$, no pressor activity was observed (Fig. 3 B3). At $\mathrm{pH} 5.2$ to 5.5 the longer incubation time, the higher the pressor activity (Fig. 4).

The pressor activity of the blood whose plasma was replaced with Ringer's solution containing albumin showed no increase following incubation, but it began to increase after the addition of an untreated dog's plasma.

\section{B) Effect of heating and dialysis}

Plasma was heated with boiling water. After 10 minute-heating of the plasma, no

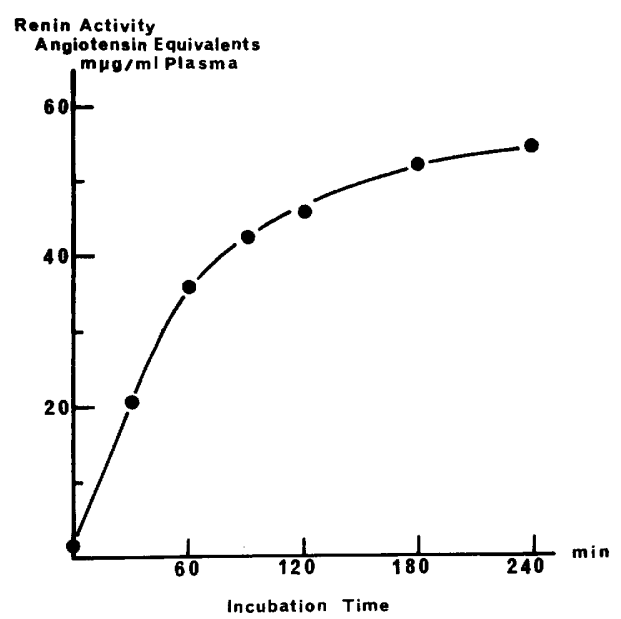

Fig. 4. The relationship between incubation time and pressor activity of the plasma. increase of pressor activity was observed by incubation (Fig. 5 G1). The maximum pressor activity of the incubated plasma was not influenced by 10 minute-heating, but the duration of the pressor activity was shortened (Fig. 5 C2).

Dialysed and then incubated plasma showed a pressor activity (Fig. 5 D2), but the pressor activity of incubated and then heated plasma was completely disappeared by dialysis (Fig. $5 \mathrm{Dl}$ ). It seems that a large molecular substance, probably protein other than albumin, is converted to heat stable and dialysable pressor substance during incubation. 

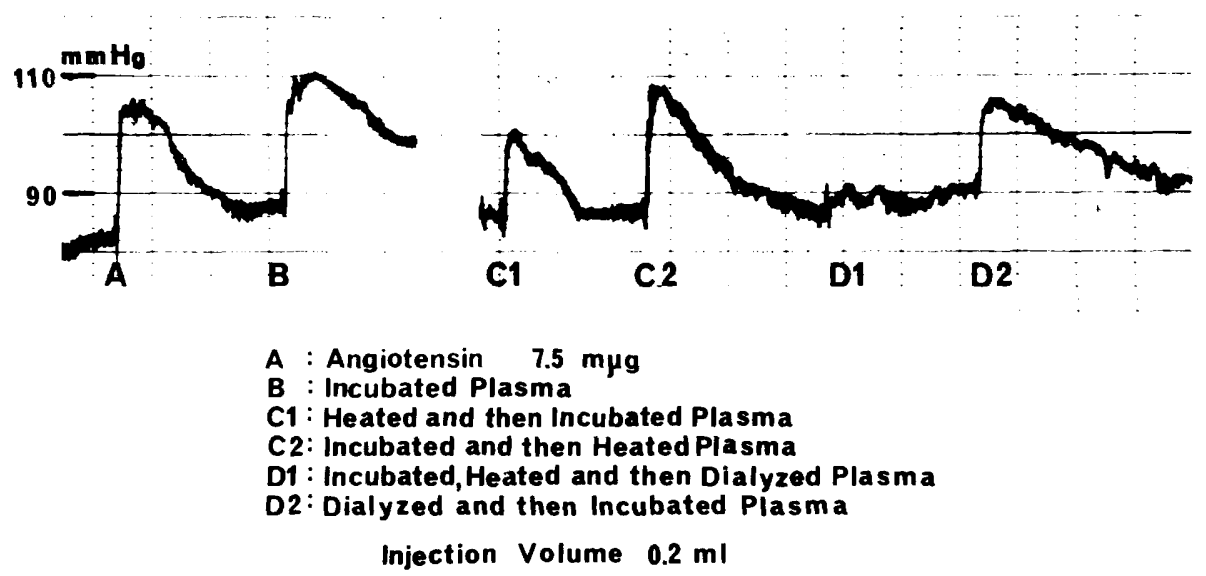

FIG. 5. Effects of heating and dialysis on the pressor activity of the plasma.

C) Extraction of the pressor substance with n-butanol

An attempt was made to extract the above mentioned heat stable and dialysable. pressor substance from the incubated plasma which was considered to contain primarily many vasoconstrictive substances. The plasma was incubated in acidic conditions $(\mathrm{pH}$ 5.2 to 5.5 ) for 30 minutes and boiled. Three $\mathrm{g}$ of $\mathrm{NaCl}$ was added to $6 \mathrm{ml}$ of the supernatant of the incubated boiled plasma, and $\mathrm{pH}$ adjusted to about 2.0 with $1 \mathrm{~N} \mathrm{HCl}$. Ten $\mathrm{ml}$ of $\mathrm{n}$-butanol was added and the mixture was shaken vigorously for 10 minutes. After centrifugation $9 \mathrm{ml}$ of the butanol layer was transfered to a flask and evaporated to a complete dryness under reduced pressure. Dried residue was dissolved by $1 \mathrm{ml}$ of distilled water and injected to rats. The blood pressure was markedly elevated. It seemed most likely that the pressor substance of the plasma was extracted into n-butanol. Seventyfive to $80 \%$ of angiotensin II was also extracted by the above procedure. On the other

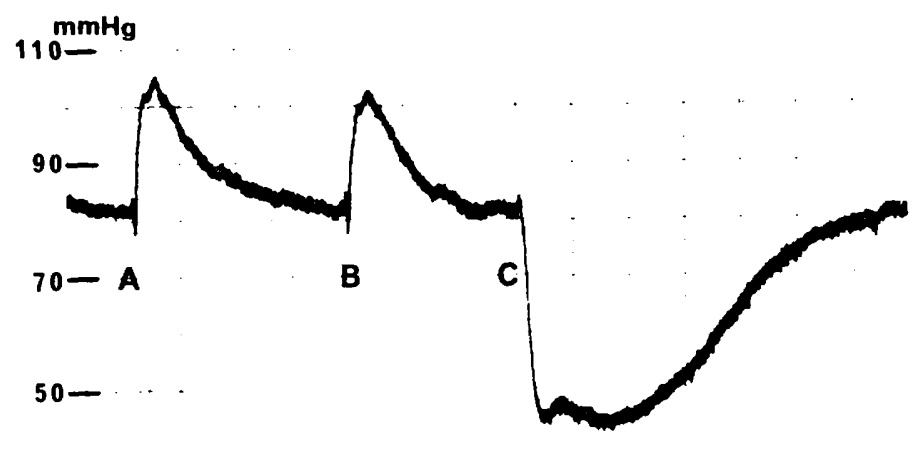

\section{A: Angiotensin $5 \mathrm{m \mu g}$ \\ B : Sample $\quad 0.2 \mathrm{ml}$ \\ C: Adrenaline $0.1 \mu \mathrm{g}$}

FJG. 6. Pressor action of angiotensin II, n-butanol extract of the plasma and adrenaline in rat following phenoxybenzamine.

Phenoxybenzamine was administered in a dose of $5 \mathrm{mg} / \mathrm{kg}$. 
hand, 50 to $150 \mu \mathrm{g}$ of norepinephrine, epinephrine or serotonin added to $5 \mathrm{ml}$ of dog's plasma was extracted within a range of 10 to $20 \%$ by the above extraction procedure.

D) Effects of phenoxybenzamine and pyrethiazine on the pressor activity of plasma

The pressor action of norepinephrine or epinephrine on rats completely disappeared following administration of phenoxybenzamine $(5 \mathrm{mg} / \mathrm{kg})$ and that of serotonin was also abolished following administration of pyrethiazine $(3 \mathrm{mg} / \mathrm{kg})$. However, the pressor action of angiotensin II and extract with nbutanol from the plasma was not influenced by the pretreatment of either phenoxybenzamine or pyrethiazine in amounts sufficient to block a comparable pressor response to norepinephrine, epinephrine or serotonin (Figs. 6 and 7). These findings strongly suggested catecholamine and serotonin took no part in the pressor factors of the incubated plasma.

\section{E) Effect of trypsin}

Ten $\mathrm{ml}$ of incubated plasma was extracted with $10 \mathrm{ml}$ of $\mathrm{n}$-butanol as described above. Subsequent to dryness the residue was dissolved with $2.5 \mathrm{ml}$ of distilled water.
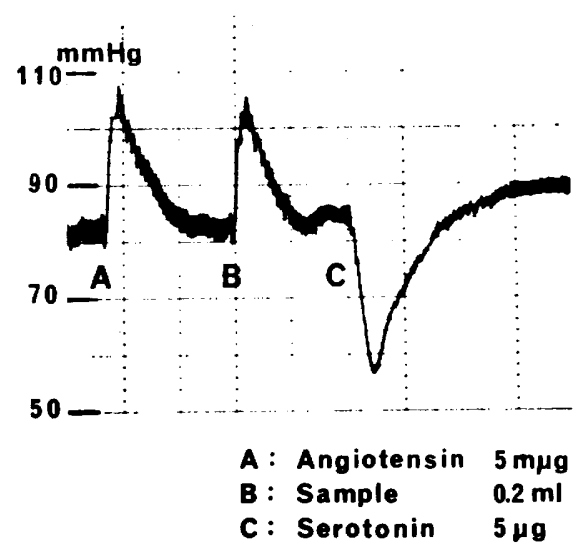

FIG. 7. Pressor action of angiotensin II, nbutanol extract of the plasma and serotonin in the rat following pyrethiazine.

Pyrethiazine was administered in a dose of $3 \mathrm{mg} / \mathrm{kg}$.

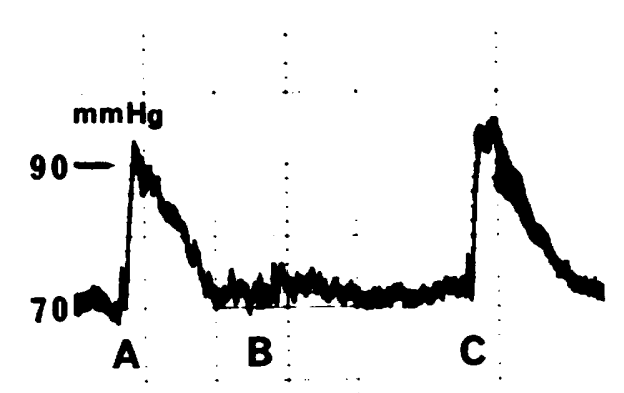

A: Sample $0.2 \mathrm{ml}$

B: A Treated with Trypsin C: Angiotensin $2.5 \mathbf{~ m \mu g}$

FIG. 8. Effect of trypsin on the pressor activity of the plasma.

One $\mathrm{ml}$ of the solution was transfered to a test tube containing $1 \mathrm{ml}$ of $0.2 \mathrm{M}$ phosphate buffer, $\mathrm{pH} 7.4$, and $0.5 \mathrm{mg}$ of trypsin $(\mathrm{NBC})$, which was incubated at $37^{\circ} \mathrm{C}$ for 30 minutes. Incubated tube was heated with boiling water for inactivation of trypsin. The pressor activity of the plasma extract completely disappeared by treatment with trypsin (Fig. 8).

\section{DISCUSSION}

When the dog kidney was perfused with the donor dog's whole blood using an artificial heart-lung apparatus, a renal vascular resistance showed a gradual increase, particularly when the perfusion pressure was reduced below $90 \mathrm{mmHg}$.

The plasma freshly prepared from the donor dog's blood showed no pressor activity in anesthetized rats, but the plasma separated from the blood perfused through the dog kidney, especially at the latter stage of perfusion, showed a pressor activity. The pressor 
activity of the latter plasma was further increased following incubation in acidic conditions $(\mathrm{pH} 5.2$ to 5.5$)$. The activity of the unincubated plasma was slightly decreased after dialysis against Ringer's solution, and markedly decreased when heated at $100^{\circ} \mathrm{C}$. But the activity of the incubated plasma, being affected by dialysis, became heat stable and sensitive to trypsin. It is assumed that a pressor substance, which is heat unstable and large molecular size, is released from the perfused kidney. It is likely that this substance produces a small molecular and heat stable substance through incubation.

The pressor substance of the incubated plasma could be extracted with n-butanol under an acidic condition ( $\mathrm{pH} 2.0$ ) with excess $\mathrm{NaCl}$, as evidenced by the presence of pressor response in the extract either before or after treatment with pentolinium. Such properties of the pressor substance coincide with those of angiotensin II.

Catecholamine and serotonin were considered as a mediator for an increase in renal vascular resistance in an isolated perfused dog kidney (2-4). In the present experiment, the pressor activity extracted into n-butanol was not modified by a pretreatment with phenoxybenzamine or pyrethiazine in rats. It is well known that the kidney destroys circulating catecholamines. An artificial heart-lung apparatus may cause hemolysis which results in the release of serotonin from platelets, but in the present experiment an increase of renal vascular resistance was not proportional to hemolysis of the perfused blood. On the other hand, bradykinin is also extracted with n-butanol in an acidic condition and it elevates blood pressure in rats, but its pressor activity is observed only in rats treated with pentolinium $(6,7)$. Bradykinin is easily destroyed when added with a kidney extract, but not affected with trypsin (8).

Skinner et al. (9), Vander and Miller (10) and other investigators (11, 12) reported that acute reduction of renal arterial pressure stimulates a secretion of renin from the kidney. The present results also showed the pressor activity in the plasma was increased when the renal perfusion pressure was lowered.

It is concluded that renin is released from the perfused kidney into the renal venous blood and the renin thus liberated produces angiotensin I. Angiotensin I is most likely converted to angiotensin II by the action of converting enzyme which is widely distributed. However, still a possibility can not be ruled out that an unknown pressor substance or substances $(13,14)$ may increase vascular resistance apart from the renin-angiotensin system.

\section{SUMMARY}

1. Renal vascular resistance increased during blood perfusion of the dog kidney with an artificial heart-lung apparatus. Reduction of the perfusion pressure markedly increased renal vascular resistance.

2. The plasma separated from the blood perfused through the kidney during an increase of renal vascular resistance showed a pressor activity in rats. The pressor activity markedly increased after incubation in acidic conditions.

3. When the dog kidney was perfused with Ringer's solution added with dog eryth- 
rocytes and human albumin the renal vascular resistance showed no increase.

4. A pressor substance in the unincubated plasma was heat unstable and nondialysable, but that in the incubated plasma was heat stable and dialysable.

5. The pressor substance in the incubated plasma could be transfered into n-butanol in acidic conditions in the presence of $\mathrm{NaCl}$.

6. The pressor substance extracted with n-butanol was inactivated by trypsin.

7. The pressor activity of the n-butanol extract was observable on rats treated with phenoxybenzamine or pyrethiamine.

8. It may be concluded that renin is released from the perfused kidney and renin thus liberated produces angiotensin II via angiotensin I.

This work was supported by the Grant from Ministry of Education, Japan.

\section{REFERENCES}

1) Yamamoto, K., Yoshimoto, S., Kishimoto, T., Shimizu, H., Hasegawa, T. and Ueda, J.: Jap. Circul. J. 31, (1967) (in press)

2) Craig, G.M., Mills, I.H., Osbaldiston, G.W. and Wise, B.L.: J. Physiol. 186, 113 (1966)

3) Barkin, M., Katz, S., Daloisio, J. And Kerr, W. K.: Surgery, Ginec. Obstet. 117, 161 (1963)

4) Hollenberg, M., Pruetr, R. and Thal, A.: J. Thorac. Cardiov. Surg. 45, 402 (1963)

5) Frick, M.H.: Nature, Lond. 187, 609 (1960)

6) Rosas, R., Gross, M. and Bohr, D.F.: Circulation Res. 16, 150 (1965)

7) Rosas, R., Mryata, T., Hoobler, S.W. and Bohr, D.F.: Proc. Soc. exp. Biol. Med. 113, 456 (1963)

8) Binia, A., Fasciolo, J.C. and Carretero, O.A.: Acta physiol. latinoam. 13, 101 (1963)

9) Skinner, S.L., McCubbin, J.W. and Page, I.H.: Science 141, 814 (1963)

10) Vander, A.J. And Miller, R.: Am. J. Physiol. 207, 537 (1964)

11) Regoli, D. and Vane, J.R.: J. Physiol. 183, 513 (1966)

12) Tagawa, H.: Tokvo J. Med. Sciences 74, 14 (1966)

13) Bohr, D.F. And Johansson, B.: Circulation Res. 19, 593 (1966)

14) Kenner, T. And WaldHÄ'sl, W:: Nature, Lond. 204, 581 (1964) 